\title{
Peer-reviewed publications by CUA members: then and now
}

\author{
Geoffrey T. Gotto, MD, FRCSC; Kourosh Afshar, MD, MSc, FRCSC, FAAP; Arash Eftekhari, MD; \\ Andrew E. MacNeily, MD, FRCSC, FAAP
}

See related article on page 391.

\section{Abstract}

Objective: The objective of this study was to assess the characteristics of publications by members of the Canadian Urological Association (CUA) over a 10-year period.

Methods: All publications by active CUA members during the periods January 1993-December 1994 and January 2003-December 2004 were reviewed.

Results: Of the 487 active members in 1993-1994, $130(26.7 \%)$ were authors a total of 649 times in 641 publications. External funding was acknowledged in 195 (30.4\%). There were 131 observational studies (20.4\%), 127 review articles $(19.8 \%), 58$ case reports $(9.0 \%), 37$ case series $(5.8 \%)$, and 21 randomized controlled trials (RCTs) $(3.3 \%)$. Of the 454 active member in 2003-2004, 139 (30.6\%) were authors a total of 748 times in 705 publications. External funding was acknowledged in 237 (33.6\%). There were 153 observational studies $(21.7 \%), 124$ review articles $(17.6 \%), 52$ case reports $(7.4 \%), 49$ case series $(7.0 \%)$, and 46 RCTs (6.5\%). There were significantly more RCTs and clinical trials in 2003-2004. The most common journal was The Journal of Urology in both eras. There were significantly more publications in The Canadian Journal of Urology, the British Journal of Urology International and the Journal of Endourology in 2003-2004. There were significantly more publications acknowledging industry funding and more publications citing more than 1 CUA member in 2003-2004. Publication intensity increased significantly from 0.67 to 0.82 publications per member, per year for the CUA as a whole. Interpretation: Scholarly activity has remained robust over the last decade with over $30 \%$ of active CUA members contributing to peer-reviewed literature. Higher levels of evidence are now observed with a greater number of RCTs. CUA members should be proud of their academic productivity.

Can Urol Assoc J 2010;4(6):385-90

\section{Résumé}

Objectif : Notre objectif était d'évaluer certaines caractéristiques d'articles publiés par des membres de l'Association des urologues du Canada (AUC) sur une période de 10 ans.

Méthodes : Tous les articles publiés signés par des membres actifs de I'AUC en janvier 1993/décembre 1994 et en janvier 2003/ décembre 2004 ont été passés en revue.
Résultats : Sur les 487 membres actifs en 1993-1994, 130 (26,7 \%) ont signé un total de 649 articles publiés dans 641 périodiques. Un financement externe a été mentionné dans 195 cas (30,4\%). On comptait 131 études d'observation (20,4\%), 127 articles de synthèse $(19,8 \%), 58$ études de cas $(9,0 \%), 37$ séries de cas $(5,8 \%)$ et 21 essais contrôlés et randomisés (3,3\%). Sur les 454 membres actifs en 2003-2004, 139 (30,6 \%) ont signé au total 748 articles publiés dans 705 périodiques. Un financement externe est mentionné dans 237 cas (33,6\%). On comptait 153 études d'observation (21,7\%), 124 articles de synthèse (17,6\%), 52 études de cas $(7,4 \%), 49$ séries de cas $(7,0 \%)$ et 46 essais contrôlés et randomisés $(6,5 \%)$. On a noté un nombre significativement plus élevé d'essais contrôlés et randomisés et d'essais cliniques en 20032004. Pour les deux époques, le périodique où le plus d'articles ont été publiés est le Journal of Urology. Le nombre d'articles publiés dans le Canadian Journal of Urology, le British Journal of Urology International et le Journal of Endourology était significativement plus important en 2003-2004, tout comme le nombre d'article faisant état d'un financement par l'industrie pharmaceutique et le nombre d'articles signés par plus d'un membre de l'AUC. Le taux de publications a considérablement augmenté, passant de 0,67 à 0,82 articles par membre, par année pour I'AUC dans son ensemble.

Interprétation : Au cours de la dernière décennie, les activités liées à la publication sont demeurées intenses, avec plus de $30 \%$ des membres actifs de I'AUC contribuant à des articles révisés par comités de pairs. Des niveaux de preuves plus élevés sont maintenant observés en raison d'un nombre plus important d'essais contrôlés et randomisés. Les membres de I'AUC devraient être fiers de leur contribution sur le plan de l'avancement scientifique.

\section{Introduction}

There is a trend toward higher quality research in medicine and surgery with an increased focus on evidence-based medicine (EBM). With this trend comes increased pressure to produce studies which provide higher levels of evidence.

Since the establishment of the Canadian Urological Association (CUA), its membership has changed dramatically. Standards for appointments at academic centres have risen, requiring fellowship training for faculty positions in most instances. In addition, many Canadian urologists now hold degrees in clinical epidemiology or medical education. There is an increasing expectation for urologists based at 
academic institutions to be involved in both basic science and clinical research. Likewise, many urologists working in community centres are now fellowship-trained and are interested in research at some level, which is facilitated by the increased involvement of industry in clinical research, particularly clinical trials.

In 1994, the Canadian Journal of Urology (CJU) was launched. This journal provided a venue for CUA members to publish in a refereed journal with a Canadian focus. More recently, in 2007, the Canadian Urological Association Journal (CUAJ) was launched as the official journal of the CUA providing even more opportunity for members to publish their original research.

Our hypothesis was that the quantity and scientific quality of publications by CUA members have improved significantly over the last decade as a result of these developments. This paper describes several trends in publications by CUA members during 2 separate eras a decade apart. These trends include changes in community and academic authorship, levels of evidence, collaboration between members and funding sources.

\section{Methods}

We retrospectively reviewed publications by the CUA membership during 2 eras separated by 10 years: January 1, 1993 to December 31, 1994; and January 1, 2003 to December 31,2004 . Published rosters of the CUA membership for these 2 time periods were used to capture all urologists eligible for study inclusion. A PubMed single-citation search was performed using the surname and first initial of the CUA member in question. We included only active members and excluded members who were categorized as senior, honorary, inactive, associate or candidate.

Each abstract and publication was reviewed to confirm that the identity of the author matched that of the CUA member. Manuscripts with authorships meeting inclusion criteria were then assessed in detail for the following predefined variables: corresponding address of CUA member, study design, journal, funding source(s) and involvement of multiple CUA members.

We defined publication intensity for 3 groups: Group 1 included CUA active members as a whole; Group 2 included CUA active and published members; and Group 3 included CUA active published members practicing in Canada at the time of publication. For Group 1, representing the CUA as whole, publication intensity was defined as unique publications per active member, per year. For Group 2, publication intensity was defined as authorships per active member, per year excluding those CUA members who had no publications. The term "authorships," as opposed to "publications," was used to account for the fact that each publication could potentially have more than one active CUA member as an author. The purpose of creating Group 2 was to specifically examine changes in publication intensity and publication characteristics of members who in fact published during the era in question. Published members were defined as members with at least 1 publication in the corresponding era. For Group 3, publication intensity was defined as authorships per active published CUA member based in Canada, per year. The purpose of creating Group 3 was to specifically examine changes in publication intensity and publication characteristics of members in Group 2 who were based in Canada at the time of publication and exclude CUA members practicing outside Canada, predominantly in the United States.

Descriptive statistics are provided. The Chi-square test was used to compare proportions between the 2 eras. Student's t-test was used to compare the continuous variables. Publication intensities were compared by calculating rate ratios and their $95 \%$ confidence intervals (S-plus, Insightful Inc., Seattle, WA).

\section{Results}

In the 1993-1994 era, there were 487 active CUA members and in the 2003-2004 era there were 454. Table 1 depicts the number of published members, authorships and unique publications during each era. Members based in Canada were examined as a subset. There was a significant increase in members based in Canada contributing to at least 1 publication between the 2 eras ( 80 vs. 108, $p=0.006$ ). However, the overall number of published members did not change during the 2 eras (130 vs. 139, $p>0.05$ ). Authorships by members based in Canada also increased significantly ( 220 vs. 545 , $p<0.001$ ) while the total number of authorships did not (649 vs. $748, p>0.05)$. The number of unique publications by members based in Canada increased significantly (204 vs. $527, p<0.001)$ while the total number of unique publications did not change significantly (641 vs. 705, $p>0.05$ ).

Publication intensity increased significantly for Groups 1

Table 1. Authorships and unique publications by the CUA membership in 1993-1994 and 2003-2004

\begin{tabular}{lccccccc}
\hline Era & Active members & \multicolumn{2}{c}{ Published members } & \multicolumn{2}{c}{ Authorships } & \multicolumn{2}{c}{ Unique publications } \\
\hline & & Canadian based & Total & Canadian based & Total & Canadian based & Total \\
\hline $1993-1994$ & 487 & $80^{*}$ & 130 & $220^{\dagger}$ & 649 & $204^{\ddagger}$ \\
\hline $2003-2004$ & 454 & $108^{*}$ & 139 & $545^{\dagger}$ & 748 & $527^{\ddagger}$ & 705 \\
\hline CUA $=$ Canadian Urological Association; ${ }^{*} p=0.006^{*} p<0.001 ;^{\ddagger} p<0.001$. & & &
\end{tabular}




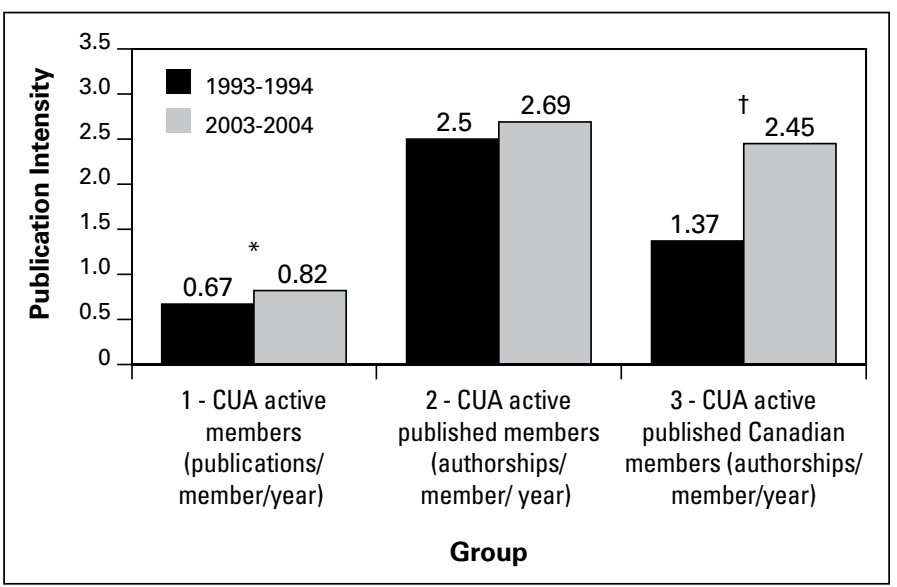

Fig. 1. Publication intensity by group and era. CUA = Canadian Urological Association. ${ }^{*}=\mathrm{RR}=1.22(95 \% \mathrm{Cl} 1.11$ to 1.35$) ; \dagger=\mathrm{RR}=1.79(95 \% \mathrm{Cl} 1.76$ to 1.80$)$.

and 3. There was a significant increase in publication intensity for Group 1 from 0.67 to 0.82 publications/member/year $(\mathrm{RR}=1.22,95 \% \mathrm{Cl} 1.11-1.35)$ (Fig. 1). Group 3 showed a significant increase in publication intensity from 1.37 to 2.45 authorships/member/year ( $\mathrm{RR}=1.79,95 \% \mathrm{Cl} 1.76-1.80)$. The publication intensity for Group 2 did not change significantly (2.50 vs. 2.69 authorships/member/year).

Figure 2 illustrates the distribution of publication types during the 2 eras. There was a significant increase in randomized controlled trials (RCTs) (21 vs. $46, p<0.05)$.
There was a significant decrease in basic science publications $(147$ vs. $114, p<0.05)$ and uncontrolled clinical trials (81 vs. $64, p<0.05$ ). There was no significant change in the number of observational studies, case series, case reports or review articles. Of note, only a single meta-analysis was published by an active CUA member during each of the 2 eras.

Figure 3 displays the most common journals in which publications by active CUA members appeared during each of the 2 eras. The Journal of Urology was the most frequent journal of publication during each of the 2 eras with no significant change in number of publications (164 vs. $169, p>0.05)$. During the most recent era, 2003-2004, the most common journals of publication were as follows, listed in order of popularity: The Journal of Urology; The Canadian Journal of Urology; Urology; British Journal of Urology (BJU) International and Journal of Endourology. There was a significant increase in publications appearing in The Canadian Journal of Urology (17 vs. $85, p<0.05)$, BJU International ( 21 vs. $54, p<0.05)$, and Journal of Endourology (12 vs. 37, $p<0.05)$.

The process for attaining funding for research has changed significantly in the recent past and this is reflected by a change in the sources of funding during the 2 eras. Figure 4 demonstrates that the number of publications declaring funding support from industry has increased significantly (47 vs. 76, $p<0.05$ ). This may represent a true increase in industry support for research or simply an increase in disclosure of such support in more recent publications. The

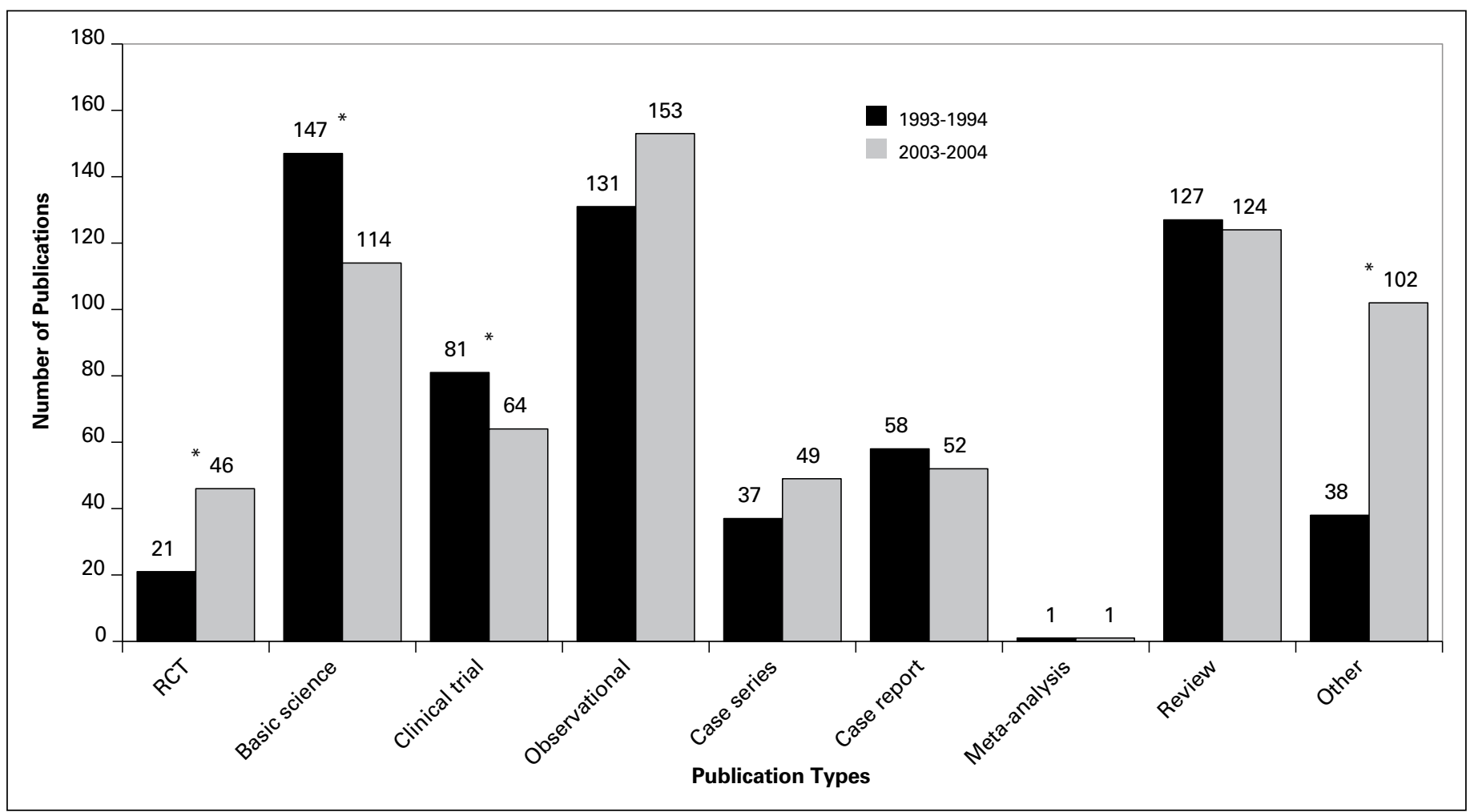

Fig. 2. Distribution of publication types by era. $\mathrm{RCT}=$ randomized controlled trial. ${ }^{*}=p<0.05$. 


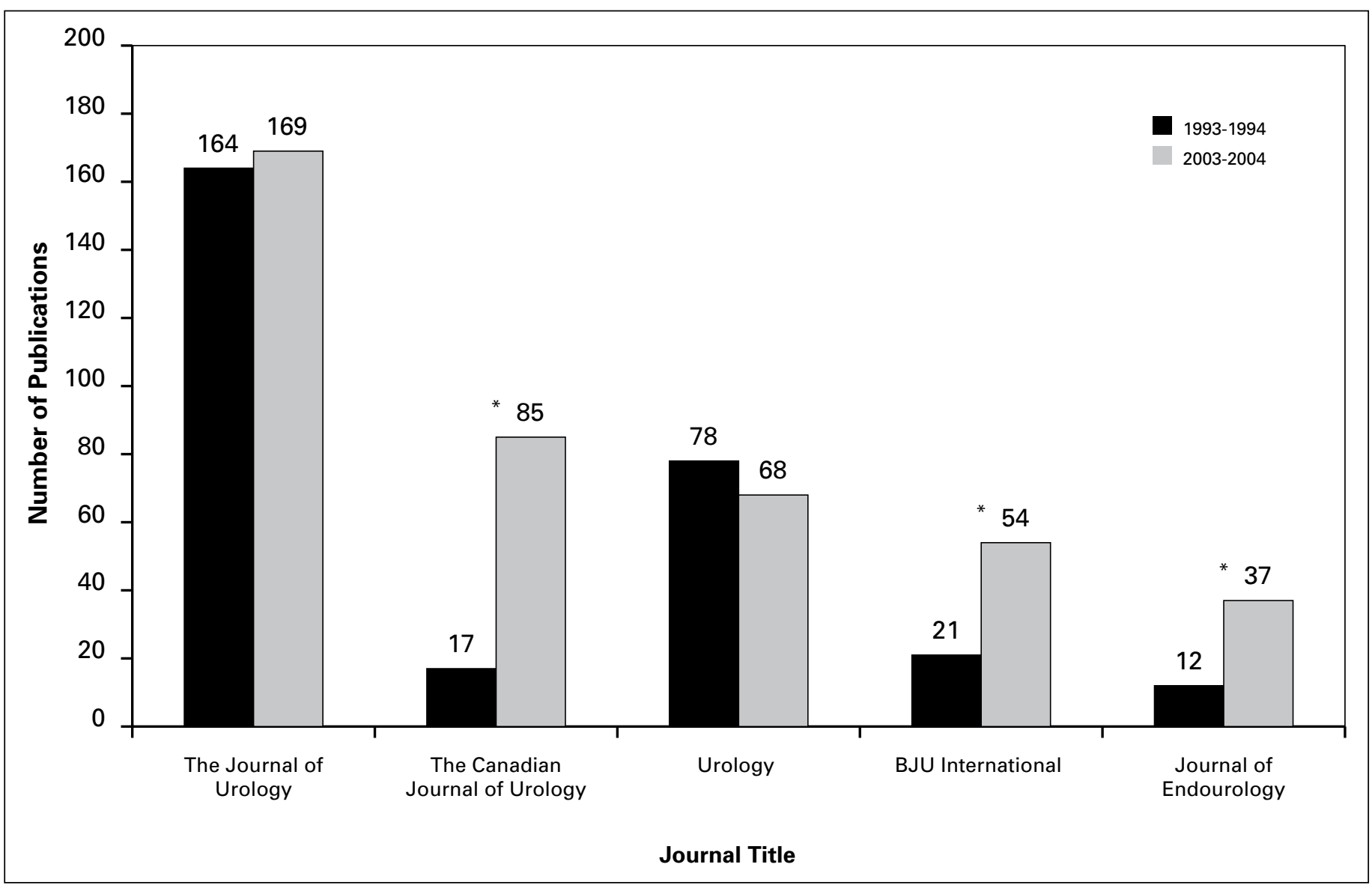

Fig. 3. Distribution of journal of publication by era. BJU $=$ British Journal of Urology. ${ }^{*}=p<0.05$.

number of publications with other funding sources declared, typically government grants or independent granting agencies, has not changed significantly (148 vs. $161, p>0.05)$. Most papers in each era had no funding sources declared (446 vs. $468, p>0.05)$.

As illustrated in Figure 5, there has been increased collaboration among CUA members, with a dramatic increase in the number of publications with more than 1 CUA member listed as an author (9 vs. 39, $p<0.05$ ).

Publications from community, or non-academic centres included 29 out of $641(4.52 \%)$ in the first era, and 9 out of $705(1.28 \%)$ in the second era. This represents a significant decrease $(p<0.001)$.

The distribution of Canadian authorships by province in each era is shown in Table 2.

\section{Discussion}

There are few studies in the literature which document changes in scholarly activity in medical or surgical specialties with time. Recently, Snow and colleagues investigated the impact of sub-specialization in pediatric urology on the academic productivity of members of The American Academy of Pediatrics Section on Urology. ${ }^{1}$ The authors found that over a 10-year time span, a higher percentage of members had published, with newer members being more productive. Interestingly, the mix of manuscript types changed with a greater percentage of review articles and a smaller percentage of case reports and basic science research. ${ }^{1}$

Galt and colleagues recently reviewed the scholarly productivity of vascular surgeons who were members of the Society for Vascular Surgery (SVS). ${ }^{2}$ They found that although scholarly activity for individual members was maintained, a smaller proportion of the SVS membership was represented in the published literature. It was hypothesized that this was related to reduced reimbursement rates and increasing clinical commitments. ${ }^{2}$

Our paper outlines several trends in publications by CUA members over the last decade. It reviews the academic productivity of CUA members and demonstrates that productivity has improved. The paper is the first of its kind to quantify academic productivity of CUA members.

Over the last decade, there has been a higher publication intensity of the CUA as a whole (Group 1) and of members based in Canada (Group 3) in particular. There has also been more collaboration between CUA members. Although there 
Table 2. Distribution of authorships by province and era

\begin{tabular}{lcc}
\hline Province & \multicolumn{2}{c}{ Authorships } \\
\hline BC & $1993-1994$ & 2003-2004 \\
\hline AB & 27 & 77 \\
\hline SK & 7 & 20 \\
\hline MN & 2 & 3 \\
\hline ON & 1 & 7 \\
\hline QC & 89 & 302 \\
\hline NB & 49 & 114 \\
\hline NS & 1 & 1 \\
\hline PEI & 27 & 21 \\
\hline NF & 0 & 0 \\
\hline Unspecified & 1 & 0 \\
\hline Total & 16 & 0 \\
\hline
\end{tabular}

was a decrease in the number of basic science publications, levels of evidence have improved with fewer uncontrolled clinical trials and greater involvement in RCTs. This information should be useful to the CUA executive and in particular to the CUA Scholarship Foundation when deliberating on the awarding of scholarships and grants.

The vast majority of publications in both eras came from academic centres or from members affiliated with an academic institution. There was a significant decrease in publications from non-academic centres across the 2 eras (4.52 vs. $1.28 \%, p<0.001)$. We hypothesize that this is likely related to an increase in workload and to the absence of protected research time for CUA members practicing in non-academic centres. This is in keeping with the findings of Galt and colleagues. ${ }^{2}$

There has been a consistent predominance of publications in The Journal of Urology, with increased publication in The Canadian Journal of Urology, BJU International, and Journal of Endourology. With the launch of CUAJ as the official journal of the CUA in 2007, it will be interesting to track the publication intensity of CUA members and the journals in which their publications appear. One would assume that with time, CUA/ will become more and more predominant.

There are limitations to our study. Due to the time involved in reviewing such a large number of publications, we chose to sample 2, 2-year intervals. This sampling represents a snapshot in time and should not be considered a complete profile of the scholarly activity of the CUA. In addition, manuscript publication is only 1 measure of scholarly activity, which does not capture teaching, mentoring, administration and leadership.

We have shown that declared extramural funding has not increased over the time period of this study. This may

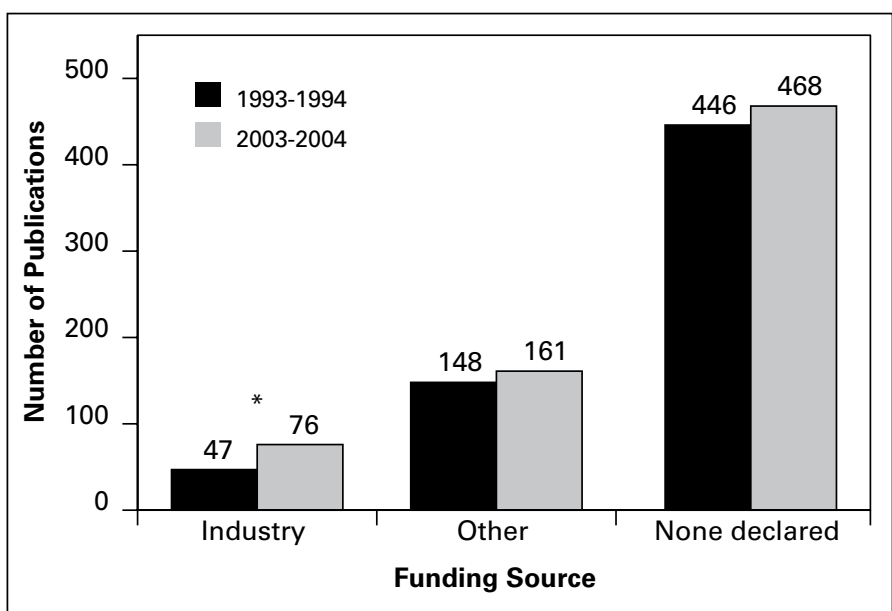

Fig. 4. Differences in funding sources by era. ${ }^{*}=p<0.05$.

reflect the difficulty academic surgeons have in the competition for such support, and may also explain the reduction in basic science publications over time. On the other hand, our search may have under-represented the true amount of peerreviewed funding if this was not consistently reported. Also, total amounts of funding are not searchable, thus one should exercise caution in equating the percentage of funded authors with the total dollar amount of peer-reviewed support. Similarly, the apparent increase in industry funding may simply represent an increase in disclosure with the recent advent of more stringent guidelines governing physicianindustry interactions.

\section{Conclusion}

Scholarly activity has remained robust over the last decade with over $30 \%$ of active CUA members continuing to contribute to the peer-reviewed literature. Significantly more publications are now emanating from members based in Canada. The percentage of funded manuscripts has remained

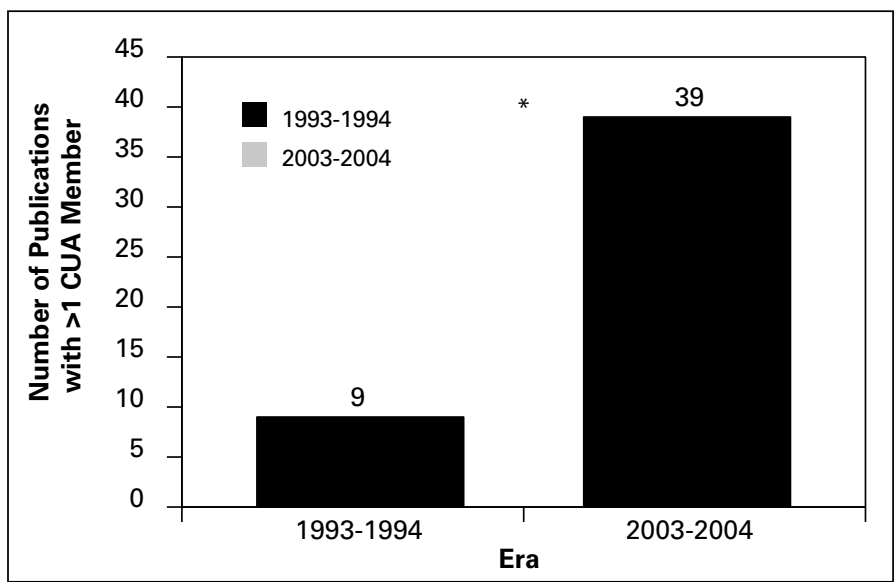

Fig. 5. Collaborations between CUA members by era. CUA = Canadian Urological Association. ${ }^{*}=p<0.05$. 
Gotto et al.

constant, although the proportion with disclosed funding from industry has increased. Higher levels of evidence are seen with a greater number of RCTs being recently published. CUA members should be proud of their academic productivity.

Department of Urologic Sciences, The University of British Columbia, Vancouver, BC

\section{References}

1. Snow BW, Owen DB, Corneli HM. Has the growth and development of subspecialization in pediatric urology affected scholarly activity? J Urol 2006;176:1868-70.

2. Galt SW, Kraiss LW, Sarfati MR. Has the changing nature of vascular surgery adversely affected scholarly activity? J Vasc Surg 2003;38:1-6.

Correspondence: Dr. Andrew E. MacNeily, K0-134 BC Children's Hospital, 4480 0ak St., Vancouver, BC V6H 3V4; fax: 604-875-2721; amacneily@cw.bc.ca

Competing interests: None declared.

This paper has been peer-reviewed. 